\title{
Comparison of Compact EBG Structures on the Mutual Coupling Reduction of Antenna Arrays
}

\author{
D. Helena Margaret, M. R. Subasree, S. Susithra, S. S. Keerthika, and B. Manimegalai
}

\begin{abstract}
Mutual coupling is a critical issue in compact array design and reducing this is one of the main efforts in Microstrip antenna array design. Periodic structures can help in this situation by suppressing surface wave propagation in a given frequency range. The purpose of this work is to show the viability of using 2D EBG structures to this aim. This paper presents a double element Microstrip antenna array inserted with the EBG structures like conventional mushroom, Jerusalem cross slot and slot loaded EBGs around 5-6 GHz. The performances are compared for mutual coupling reduction. Simulated results verify the improvement in performance of the antenna array compared to the array antenna without EBG. The slot loaded EBG is found to be good showing a 5.8dB mutual coupling reduction.
\end{abstract}

Index Terms-Electromagnetic bandgap (EBG) structures, microstrip antenna arrays, mutual coupling, surface wave.

\section{INTRODUCTION}

Microstrip antenna arrays have been popular for decades because they exhibit a low profile, small size, lightweight, low manufacturing cost, high efficiency, and an easy method of fabrication and installation. Furthermore, they are generally economical to produce since they are readily adaptable to hybrid and monolithic integrated circuits fabrication techniques at radio frequency (RF) and microwave frequencies however, significant degradation of performance happens due to mutual coupling between the antenna elements[1]. An antenna that is placed on a highpermittivity dielectric substrate may couple power into substrate modes. As substrate modes do not contribute to the primary radiation pattern, these modes are a loss mechanism which reduces as high as $60 \%$ of the radiated power and reduce the antenna efficiency.

Various techniques are explicitly designed to suppress the surface wave. A straightforward way to reduce the mutual coupling of monopole antennas on high-impedance ground plane was developed in [2]. EBGs built in microstrip technology have gained much attention in the last years, following their application in antenna technology introduced in [3]-[5]. The Electromagnetic Bandgap (EBG) structures are periodically arranged metallic or dielectric elements that exhibits one or more forbidden frequency bands where surface waves are prevented to propagate. As EBG structures exhibit forbidden bandgap by suppressing

Manuscript received March 9, 2013; revised May 16, 2013.

D. Helena Margaret, M. R. Subasree, S. Susithra, S. S. Keerthika are with Velammal College of Engineering and Technolgy India (email:silverstar.suba@gmail.com)

B. Manimegalai is with Thiagarajar College of Enginering. surface-wave propagation, the directions of research has been in suppression of parallel plate noise in printed circuit boards, integrated circuits and high speed circuits in general, low-cost filter design and construction[6]-[8], performance improvement in Microstrip antennas and mutual coupling reduction in antennas arrays[9]-[12].

Various 1D and 2D EBG structures have been studied extensively in the last decade. The uniplanar EBG (UCEBG) can suppress TM modes and 2D structures can suppress both TM and TE surface modes. When the EBG parameters are properly designed, the pronounced surface waves are suppressed resulting in low mutual coupling.

In this paper, various EBG structures like conventional mushroom, Jerusalem cross slot and slot loaded EBGs are inserted between a two element microstrip line fed monopole antenna array to reduce the strong mutual coupling of coupled microstrip antennas. The performance and the mutual coupling are compared with and without the EBG structures with the Method of Moment simulations.

\section{EBG STRUCTURE CONFIGURATION}

The conventional mushroom like EBG structure was proposed in [3], [4]. It consists of four parts: a ground plane, a dielectric substrate, metallic patches and connecting vias as shown in Fig. 1(a). The operation mechanism of this EBG structure can be explained by an LC filter array which is shown in Fig. 1(b), the inductor L results from the current flowing through the vias, and the capacitor $\mathrm{C}$ due to the gap effect between the adjacent patches. For an EBG structure with patch width $W$, gap width $g$, substrate thickness $h$ and dielectric constant $\varepsilon_{r}$, the values of the inductor $L$ and capacitor $\mathrm{C}$ are determined by the following formula:

$$
\begin{aligned}
& L=\mu_{0} \mu_{r} \\
& C=\frac{(w+g) \epsilon_{0}\left(1+\epsilon_{r}\right)}{\pi} \\
& B W=\frac{1}{\eta_{0}} \sqrt{L / C} \\
& \omega=\frac{1}{\sqrt{L C}}
\end{aligned}
$$

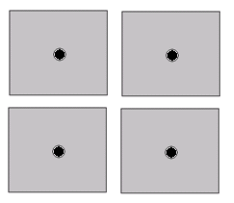

(a)

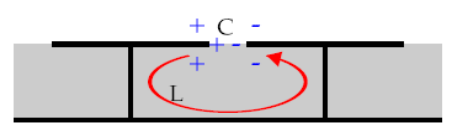

(b)
Fig. 1. Conventional mushroom EBG (a) EBG Cells (b) equivalent lumpcircuit elements of a typical EBG unit cells. 
These formulas (1)-(4) are very simple and but their results are not very accurate. They are used to get an initial engineering estimation. To get the accurate band gap characteristics, the FDTD method can be used. Based on full wave analysis, the designed EBG structures follow the following expressions for the parameters:

$W=0.12 \lambda_{G H z}, g=0.02 \lambda_{G H z}, h=0.04 \lambda_{G H z}, \varepsilon_{r}=4.4$ and the via radius is $0.005 \lambda_{G H z}$

The resulting dimensions of the EBG unit cells are $w=5.5 \mathrm{~mm}, g=1 \mathrm{~mm}$ and via radius $0.25 \mathrm{~mm}$. The EBGs are etched on a dielectric substrate FR4 epoxy $\left(\varepsilon_{r}=4.4\right)$ with a thickness of $2 \mathrm{~mm}$.

The EBG structures (conventional mushroom, Jerusalem cross slot and slot loaded EBGs) which are used in the design for the reduction of mutual coupling are shown in Fig. 2. The lattice in Fig. 2 (a) is the conventional mushroom structure which consists of square metal patches connected to the ground plane by metal via pins in the center of the patch. The lattice in Fig. 2 (b) is the Jerusalem cross slot EBG structure, while the lattice in Fig. 2 (c) consists of metal patches with slots on four sides. Gray parts in the figure represent metallic periodic structure which is etched on a dielectric substrate. Each element of this EBG lattice consists of a square metal patch with a slots cut in it, as shown in Fig. 2.

The patch is connected to the solid lower ground plane by a metal plated via. By cutting the metal patch, additional capacitances are introduced along with the capacitance formed by the gap between the metallic patches. Furthermore, in these structures it is very easy to adjust the capacitance amount by changing the slot dimensions. For example, increasing the slots, more capacitance will be introduced and vice versa. Thus variation of the slots results in the tuning of the frequency bandgap position.

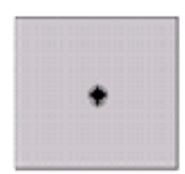

(a)

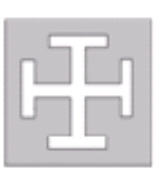

(b)

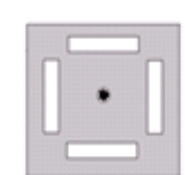

(c)
Fig. 2. EBG unit Cells (a)Conventional mushroom EBG (b) Jerusalem cross slot EBG (c) Slot loaded EBG.

\section{BAND GAP CHARACTERIZATION}

A $3 \times 3$ EBG patch array has been simulated. The Method of Moment is applied to design these EBG structures (Agilent's ADS Software). The array is built on a $1.6 \mathrm{~mm}$ thick substrate with the relative permittivity of 4.4. The length of the square patch (W) is $5.5 \mathrm{~mm}$ and the distance between the adjacent patches is $g=1 \mathrm{~mm}$. The period of the lattice is $W+g=6.5 \mathrm{~mm}$. The method of suspended Microstrip is applied to measure the bandgap characterization of the EBG structures. A distinctive stopband has been observed in the desired 5-6 GHz.

\section{Mutual Coupling Reduction}

The microstrip antenna arrays on a thick and high permittivity substrate suffers from strong mutual coupling because of the surface waves. The suppression of surface waves plays a useful role in improving the radiation efficiency of antennas and also allows the control of unwanted side and back lobes in the pattern. This capability of EBG structures can be evaluated experimentally using surface wave measurements.

The setup model used to demonstrate the mutual coupling reduction is shown in Fig. 3. It consists of a two element microstrip monopole antenna array having a resonant frequency of $5.5 \mathrm{GHz}$ placed $\lambda / 2$ apart, where $\lambda$ is the freespace wavelength.

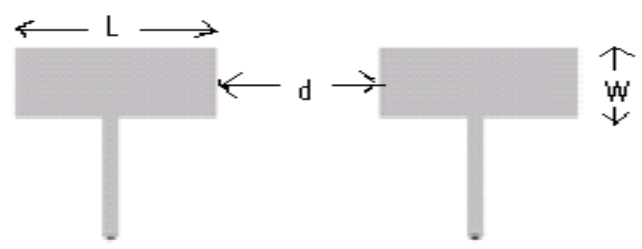

Fig. 3. Monopole antenna array.

The size of the antenna is $W \times L=12 \mathrm{~mm} \times 24 \mathrm{~mm}$. The antenna is excited by a 50-microstrip line with $W \times L=$ $1.9 \mathrm{~mm} \times 16 \mathrm{~mm}$ and the distance $\mathrm{d}$ between the antennas is $30 \mathrm{~mm} \quad(\approx 0.5 \lambda)$. The antenna is etched on FR4 epoxy substrate with a thickness of $2 \mathrm{~mm}$ and dielectric constant of 4.4 .

Since the EBG's have the capability to suppress surface waves, one column of EBG is inserted between the antennas to reduce the mutual coupling, as shown in Fig. 4.

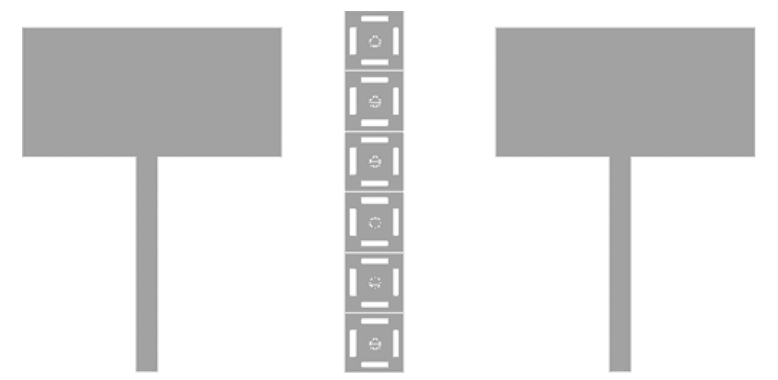

Fig. 4. Microstrip monopole antennas separated by the slot loaded EBG structure for a low mutual coupling. One column of EBG patches is used.

Agilent's Advanced Design System software based on Method of Moments (MOM) is used to simulate the monopole microstrip antennas. Various EBG structures are inserted between the antennas to reduce the mutual coupling.

\section{COMPARISON OF THE EBG STRUCTURES}

Three different EBG cases, which are the modified conventional mushroom EBG (mushroom EBG, Jerusalem cross slot, Slot loaded EBG) are analyzed for mutual coupling reduction. The EBGs are designed on the fr4 substrate with thickness $h=1.6 \mathrm{~mm}$ and relative permittivity of 4.4. The radius of the via pins, where present, was kept constant at $0.25 \mathrm{~mm}$. During the comparison, the antenna size, substrate properties, and antenna distance in all the structures are kept the same as in the mushroom EBG case.

Fig. 5 shows the return loss of the antenna array with and without EBG. It is observed that the antennas with and without EBG structure resonate around 5.6 GHz. The 
mutual coupling results are shown in Fig. 6. The results show a very good reduction in coupling between the antennas due to the EBG structures.

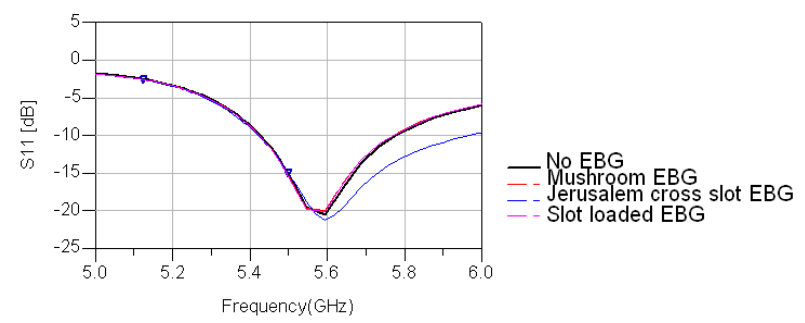

Fig. 5. Return loss of the array structure.

Without the EBG structures, the antennas show a strong mutual coupling of $-37.5 \mathrm{~dB}$. When the EBG structures are employed, the mutual coupling level changes according to the type of EBG structure used. The Jerusalem EBG structure reduces the coupling level by $3.817 \mathrm{~dB}$ and the mushroom structure provides a coupling reduction of 4.58 $\mathrm{dB}$ with respect to the antenna without EBG. The slot loaded EBG is found to be better showing a $5.8 \mathrm{~dB}$ mutual coupling reduction compared to antenna without EBG. The slots in the structure produce increased capacitive effects in the structure which accounts for this low mutual coupling between the antennas.

Table I summarizes the mutual coupling between the antenna array elements and the bandwidth of the antenna structure with and without EBGs. The Jerusalem slot EBG structure is found to have a wider bandwidth.

TABLE I: MUTUAL COUPLING AND BANDWIDTH OF THE ANTENNA ARRAY

\begin{tabular}{|l|l|l|}
\hline Structure & Mutual coupling & Bandwidth \\
\hline Without $\boldsymbol{E B G}$ & $-37.5 \mathrm{~dB}$ & $350 \mathrm{MHz}$ \\
\hline Mushroom EBG & $-42.08 \mathrm{~dB}$ & $350 \mathrm{MHz}$ \\
\hline $\begin{array}{l}\text { Jerusalem Cross } \\
\text { slot EBG }\end{array}$ & $-41.667 \mathrm{~dB}$ & $575 \mathrm{MHz}$ \\
\hline Slot loaded $\boldsymbol{E B G}$ & $-43.33 \mathrm{~dB}$ & $350 \mathrm{MHz}$ \\
\hline
\end{tabular}

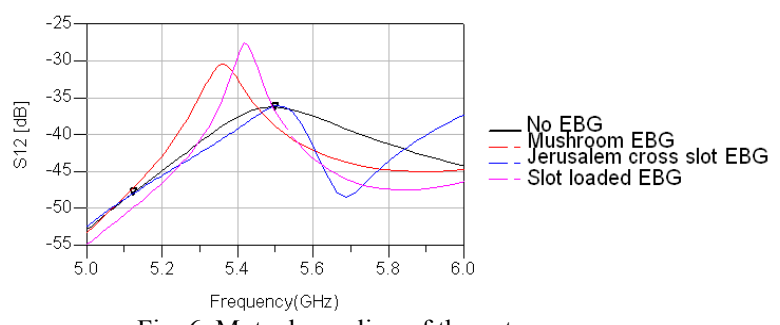

Fig. 6. Mutual coupling of the antenna array.

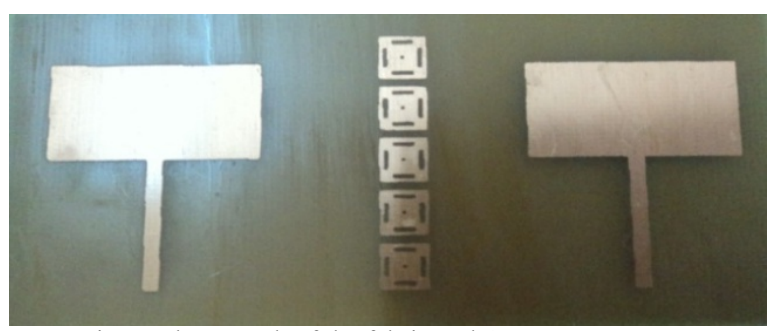

Fig. 7. Photograph of the fabricated Antenna structure. separated by EBG structures.

\section{CONCLUSION}

The performance of a double element microstrip antenna array inserted with the EBG structures like conventional mushroom, Jerusalem cross slot and slot loaded EBGs around 5-6 GHz is examined for mutual coupling reduction. Simulated results verify the improvement in performance of the antenna array compared to the array antenna without EBG. A significant improvement of compactness and performance is observed.

\section{FUTURE WORK}

The prototype of the antenna structure is fabricated. It consists of Antenna structures separated by a column of slot loaded EBG structures.

In future, the measured results will be compared with the simulated ones.

\section{REFERENCES}

[1] P. Barthia, I. Bahl, R. Garg, and A. Ittipiboon, Microstrip Antenna Design, Handbook. Boston, MA: Artech House, 1987.

[2] H. Xin, K. Matsugatani, M. Kim, J. Hacker, J. A. Higgins, M. Rosker, and M. Tanaka, "Mutual coupling reduction of low-profile monopole antennas on high-impedance ground plane," Electron. Lett., vol. 38, no. 16, pp. 849-850, 2002.

[3] D. Sievenpiper, L. Zhang, F. J. Boas, N. G. Alexópoulos, and E. Yablonovitch, "High-impedance electromagnetic surfaces with a forbidden frequency band," IEEE Trans. Microw. Theory Tech., vol. 47, no. 11, November 1999.

[4] D. Sievenpiper and E. Yablonovitch, "Circuit and method for eliminating surface currents on metals," US Patent 60/07/79953, Mar. $30,1998$.

[5] R. Gonzalo, P. D. Maagt, and M. Sorolla, "Enhanced patch-antenna performance by suppressing surface waves using photonic-bandgap substrates," IEEE Trans. IEEE Trans. On Microwave Theory and Tech., vol. 47, no. 11, November, 1999.

[6] S. D. Rogers, "Electromagnetic-bandgap layers for broadbandsuppression of TEM modes in power planes," IEEE Trans. Microw. Theory Tech., vol. 53, no. 8, pp. 2495-2505, Aug. 2005.

[7] R. Abhari and G. V. Eleftheriades, "Metallo-dielectric electromagnetic bandgapstructures for suppression and isolation of the parallel-plate noise in high-speed circuits," IEEE Trans. Antennas Propag., vol. 51, no. 6, pp. 1629-1639, June 2003.

[8] W. Menzel, L. Zhu, K. Wu, and F. Bögelsach, "On the design of novel compact broad-band planar filter," IEEE Trans. Microwave Theory Tech., vol. 51, no. 2, pp. 364-369, February 2003.

[9] Z.-C. Hao, J.-S. Hong, J. P. Parry, and D. P. Hand, "Ultra-wideband band pass filter with multiple notch bands using non uniform periodical slotted ground structure," IEEE Trans. Microwave Theory Tech., vol. 57, no. 12, pp. 3080-3088, December 2009.

[10] F. Yang and Y. R. Samii, "Microstrip antennas integrated with electromagnetic band-gap (EBG) structures: a low mutual coupling design for array applications," IEEE Trans. Antennas Propag, vol. 51, no. 10, pp. 2936-2946, October 2003.

[11] L. Yang, M. Fan, F. Chen, J. Z. She, and Z. H. Feng, "A novel compact electromagnetic-bandgap (EBG) structure and its applications for microwave circuits," IEEE Trans. Microwave Theory Tech., vol. 53, no. 1, pp. 183-190, January 2005.

[12] H. H. Xie, Y. C. Jiao, L. N. Chen, and F. S. Zhang, "An effective analysis method for EBG reducing patch antenna coupling," Progress In Electromagnetics Research Letters, vol. 21, pp. 187-193, 2011

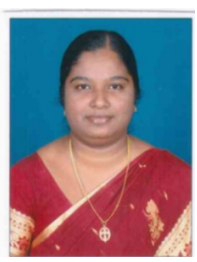

D. Helena Margaret completed her B.E., (electronics and communication engineering) from Manonmaniam Sundaranar University and M.E (microwave and optical engineering) from Madurai Kamaraj University in 1997 and 2000 respectively and is currently pursuing her Ph.D. in the field of Antennas. She is working as assistant professor in Velammal College of Engineering and Technology, Madurai. She has International conferences 


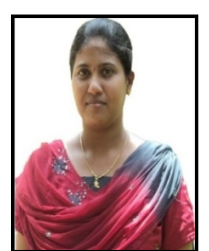

M. R. Subasree completed her B.E., in electronics and communication engineering in Velammal College of Engineering and Technology, Madurai India in 2012. Currently she is doing her master's degree (wireless technologies) at Thiagarajar College of Engineering, Madurai. Her primary area of interest is in Electromagnetic band gap structures.

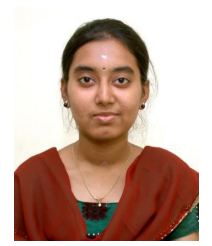

S. Susithra has completed B.E., in electronics and communication Engineering in Velammal College of Engineering and Technology, Madurai India in 2012. Currently she is pursuing Master's degree (VLSI design) at mepco schlenk engineering College, Sivakasi, India.

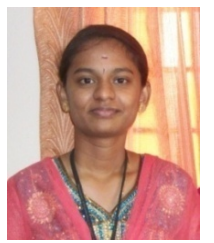

S. S. Keerthika completed her B.E., in electronics and communication Engineering in Velammal College of Engineering and Technology, Madurai India in 2012. Currently she is doing her Master's degree (optical communication) at A.C College of Engineering and Technology, Karaikudi, India.

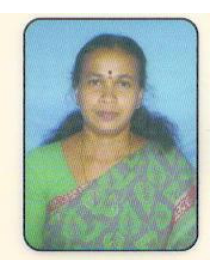

B. Manimegalai received B.E. (electronics and communication) and M.E. (microwave and optical engg) degrees from Madurai Kamaraj University in 1990 and 1993 respectively and Ph.D. degree from Anna University in 2009 titled Development of Fractal antennas for Multiband Wireless applications. She is working as Assistant Professor in Electronics and Communications Engineering department of Thiagarajar College of Engineering, Madurai. She has published Handbooks, Laboratory manuals, research papers in many National and International Conferences. She has published 5 papers in International Journals including IEEE Antennas and Wireless propagation journals. Her present area includes of design, numerical modeling and development of Compact antennas, Wide band and Multiband antennas, conformal antennas for wireless, biomedical and Terahertz applications. 